EDITORIAL

\title{
OJPH: New Editor-in-Chief, Enduring Public Health Challenges
}

\section{Sheryl L. Chatfield}

Kent State University, College of Public Health, Kent, $\mathrm{OH}$

Published January 28, 2022 https://doi.org/10.18061/ojph.v4i2.8774

On behalf of the Ohio Public Health Association (OPHA) and the many individuals who have contributed to this issue, I am pleased to present Volume 4, Issue 2 of the Ohio Journal of Public Health (OJPH). As I write this editorial, the Omicron variant of coronavirus disease 2019 (COVID-19) has been identified in increasing numbers and in an increasing number of locations, including Ohio. Although there are many unknowns about Omicron, including typical seriousness of symptoms, level of protection offered by vaccination and boosters, and the range of feasible strategies for controlling the spread, it is clear to me and borne out by the papers published in this issue that while COVID-19 is a public health issue of profound importance and longevity, a range of other public health concerns continue to impact Ohioans. Some, including unequal access to health care and prevalence of mental illness, may be exacerbated by the pandemic and emergence of variants. That said, these and others - trends in chronic disease, shortage of care workers, substance abuse and misuse-comprised major public health concerns in Ohio before the pandemic and are likely to remain key concerns, including in some epidemiologist-suggested potential scenarios where COVID-19 transforms from pandemic to endemic. ${ }^{1}$

Like many others, I am doing my best to engage in behaviors that promote my mental and physical health, while at the same time I struggle with uncertainty and pandemic-associated weariness. One thing I look forward to in our post-COVID pandemic future, is the opportunity for public health professionals to critically reflect on lessons learned from multiple aspects of the pandemic, including environmental issues. I became concerned about the environmental impact of COVID-19 during the early days of the pandemic as I started to see masks, mostly disposable but sometimes reusable, scattered near the entrance of any location that overtly enforced mask-wearing. I took the cover photo during a walk on one of the sunny and pleasant days this fall and selected it due to the color contrast between the mask and leaves. Sadly, this was one of several discarded masks I saw and captured on that day walking around a geographically compact area. Ideally future public health professionals will find a way to balance ready availability of masks with sustainability, perhaps by using designs that have recyclable aspects and by increasing availability of appropriate disposal methods.

As I suggested previously, the papers in this issue reflect a range of topics of importance to public health practitioners, researchers, and educators. King and colleagues contributed the only COVID-19 focused manuscript in this issue in which they explored relationships among preexisting health diagnoses, risk perceptions, and self-reported compliance with social distancing recommendations. Schmiederer describes the public health value and critical need for home health aides, which is an 
issue of increasing importance, given that the proportion of Ohioans 60 years of age or over is projected to increase by $30 \%$ by the year $2030 .{ }^{2}$ Substance abuse and misuse continue to be critical concerns in Ohio and comprise the focus of 3 papers, including a research brief about medicationassisted treatment. Acquavita and colleagues qualitatively considered the perspectives of law enforcement and treatment providers along with those of individuals with substance use disorders, while Jacobson and colleagues described the challenges in conducting a review of health care records to identify women who might benefit from integrated maternal health and opioid use disorder treatment during pregnancy. Other topics explored by authors in this issue include associations between socioeconomic factors and trends in chronic disease, how charity care practices in nonprofit hospitals in Columbus compare with those in peer cities, the development and potential value of the Ohio Equity Institute data portal to facilitate credible evaluation of services provided by community-based organizations, and disparate health outcomes among adults in Ohio who reflect sexual and gender minorities.

In closing my first editorial, I want to acknowledge the many sources of support that make this journal possible. Publication of OJPH is a team effort that involves invaluable contributions from the Ohio Public Health Association, the dedicated and motivated members of the journal editorial board, the online journal staff from The Ohio State University Libraries, and our amazing copy editor, Darlene Bowers. I also want to say a special thank you to Cheryl Davis from OPHA for her invaluable assistance provided to me during the processing of this issue. And, finally, I express my sincere gratitude to Dr. Amy Ferketich, founding editor-in-chief of OJPH, who started training me in early 2021 and has continued to be an exceptional source of information and support. Through the first 7 issues of OJPH, Dr. Ferketich established procedures from scratch while ensuring OJPH reflects a broad range of high-quality content of interest to public health practitioners, researchers, and educators in Ohio. It is both my honor and challenge to follow in her footsteps.

\section{REFERENCES}

1. Philips N. The coronavirus is here to stay: here's what that means. Nature. 2021;590:382-384.

https://doi.org/10.1038/d41586-021-00396-2

2. Ohio Department of Aging. State plan on aging 2019-2022. http://www.advancingstates.org/sites/default/files/ Ohio_State_Plan_19-22.pdf 